\title{
Strongly Reducing (Diarylamino)benzene-Based Covalent Organic Framework for Metal-Free Visible Light Photocatalytic $\mathrm{H}_{2} \mathrm{O}_{2}$ Generation
}

Chidharth Krishnaraj, Himanshu Sekhar Jena, Laurens Bourda, Andreas Laemont, Pradip Pachfule, Jérôme Roeser, C. Vinod Chandran, Sander Borgmans, Sven M. J. Rogge, Karen Leus, Christian V. Stevens, Johan A. Martens, Veronique Van Speybroeck, Eric Breynaert, Arne Thomas,* and Pascal Van Der Voort*

Cite This: J. Am. Chem. Soc. 2020, 142, 20107-20116

Read Online

ACCESS | 네 Metrics \& More | 国 Article Recommendations | sl Supporting Information

ABSTRACT: Photocatalytic reduction of molecular oxygen is a promising route toward sustainable production of hydrogen peroxide $\left(\mathrm{H}_{2} \mathrm{O}_{2}\right)$. This challenging process requires photoactive semiconductors enabling solar energy driven generation and separation of electrons and holes with high charge transfer kinetics. Covalent organic frameworks (COFs) are an emerging class of photoactive semiconductors, tunable at a molecular level for high charge carrier generation and transfer. Herein, we report two newly designed two-dimensional COFs based on a (diarylamino)benzene linker that form a Kagome (kgm) lattice and show strong visible light absorption. Their high crystallinity and large surface areas (up to $1165 \mathrm{~m}^{2} \cdot \mathrm{g}^{-1}$ ) allow efficient charge transfer and diffusion. The diarylamine (donor) unit promotes strong reduction properties, enabling these COFs to efficiently reduce oxygen to form $\mathrm{H}_{2} \mathrm{O}_{2}$. Overall, the use of a metal-free, recyclable photocatalytic system

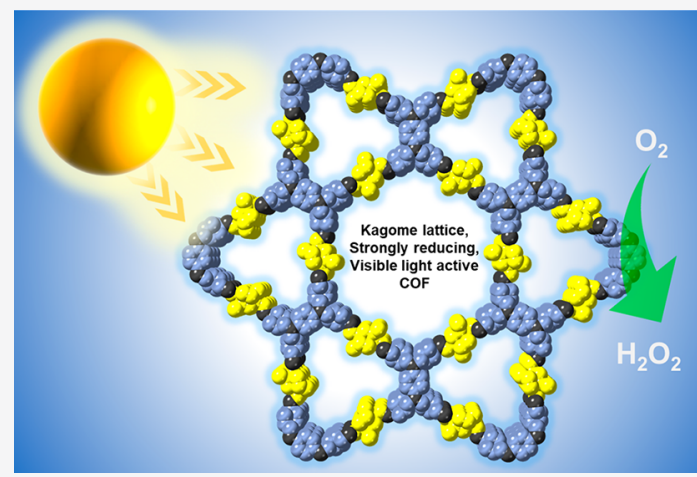
allows efficient photocatalytic solar transformations.

\section{INTRODUCTION}

Covalent organic frameworks (COFs) are an emerging class of crystalline porous organic materials, built up from covalently linked organic molecules. ${ }^{1}$ Tuning the reticular chemistry leading to these structures enables synthesis of crystalline, photoactive, porous, and highly stable materials, providing an optimal platform for photocatalysis. ${ }^{2}$ The main factors required for an efficient photocatalyst are (i) suitable band gaps, (ii) proper band position alignments, (iii) strong light absorption, (iv) efficient charge carrier generation, (v) high charge transfer kinetics, (vi) low recombination, and (vii) efficient diffusion and active sites. ${ }^{3-5}$ By modifying the starting linker, COFs can be functionalized at a molecular level to optimize these properties. Functionalities such as triazine, porphyrin, and benzothiadiazole have been incorporated into COFs to improve charge transfer kinetics and charge carrier separation. $^{2,6}$ By incorporating alternating donor-acceptor moieties into an extended framework, several COFs have been rendered suitable for photocatalysis. ${ }^{7,8}$ There remains, however, extensive potential to design COFs optimized for photocatalysis by tweaking their structures at a molecular level.

In photocatalysis, COFs have been mainly limited to hydrogen evolution reaction through water splitting, ${ }^{9} \mathrm{CO}_{2}$ reduction, ${ }^{10}$ degradation of organic pollutants, ${ }^{11}$ oxidative hydroxylation of arylboronic acids to form phenols, ${ }^{12}$ oxidation of anisoles to sulfoxides, ${ }^{13}$ reductive dehalogenation of phenacyl bromide, ${ }^{14}$ oxidative coupling of amines to imines, ${ }^{15}$ etc. To the best of our knowledge, COFs enabling photocatalytic reduction of molecular oxygen to produce $\mathrm{H}_{2} \mathrm{O}_{2}$ have not yet been reported.

Hydrogen peroxide $\left(\mathrm{H}_{2} \mathrm{O}_{2}\right)$ is a widely used chemical with applications as an antiseptic, a disinfectant, and a bleaching agent, and as an oxidizer in synthetic pathways. It is produced on a large scale through multistep hydrogenation of anthraquinone moiety using $\mathrm{H}_{2}$, followed by oxidation using $\mathrm{O}_{2} \cdot{ }^{16}$ Direct production of $\mathrm{H}_{2} \mathrm{O}_{2}$ with $\mathrm{Au}-\mathrm{Pd}$ bimetallic catalysts using $\mathrm{H}_{2}$ and $\mathrm{O}_{2}$ gas mixtures was also investigated. ${ }^{17}$ Alternative approaches involving electrochemical, photocatalytic, and photoelectrochemical processes were also studied for this purpose. ${ }^{18,19}$ Recently, Yamashita and co-workers have developed a two-phase system for the photocatalytic $\mathrm{H}_{2} \mathrm{O}_{2}$

Received: September 9, 2020

Published: November 13, 2020 
production. The photocatalyst is dispersed in one phase (benzyl alcohol) where oxidation reaction takes place, whereas in the other phase (water) reduction of $\mathrm{O}_{2}$ to form $\mathrm{H}_{2} \mathrm{O}_{2}$ occurs. $^{20,21}$ This promoted separation and avoided catalytic decomposition of $\mathrm{H}_{2} \mathrm{O}_{2}$. Photocatalytic pathways provide a sustainable route for $\mathrm{H}_{2} \mathrm{O}_{2}$ synthesis as they involve (i) a onestep reaction, (ii) utilization of green reagents, and (iii) light as the source of energy. Especially, the use of only visible light for the production of $\mathrm{H}_{2} \mathrm{O}_{2}$ is considered to be particularly sustainable. ${ }^{22}$ Photocatalytic $\mathrm{H}_{2} \mathrm{O}_{2}$ synthesis is performed by irradiating water saturated with oxygen in the presence of a semiconductor, using alcohols as the electron and proton donors. Excitation of the semiconductor produces electron $\left(\mathrm{e}^{-}\right)$and hole $\left(\mathrm{h}^{+}\right)$pairs. The holes oxidize the alcohol and produce aldehyde and protons (eq 1). Simultaneously, the electrons promote a two-electron reduction of oxygen to give $\mathrm{H}_{2} \mathrm{O}_{2}$ (eq 2). ${ }^{22}$ A side reaction, detrimental to the desired twoelectron reduction of oxygen, involves one-electron reduction to produce a superoxide anion. Hence an efficient system to selectively perform the two-electron reduction is required.

$$
\begin{aligned}
& \mathrm{R}-\mathrm{CH}_{2} \mathrm{OH}+2 \mathrm{~h}^{+} \rightarrow \mathrm{R}-\mathrm{CHO}+2 \mathrm{H}^{+} \\
& \mathrm{O}_{2}+2 \mathrm{H}^{+}+2 \mathrm{e}^{-} \rightarrow \mathrm{H}_{2} \mathrm{O}_{2} \quad(0.68 \mathrm{~V} \text { vs NHE })
\end{aligned}
$$

Wurster-type systems are classic examples of phenylenediamine units displaying redox activity (Figure 1a). ${ }^{2,25}$ Phenyl-

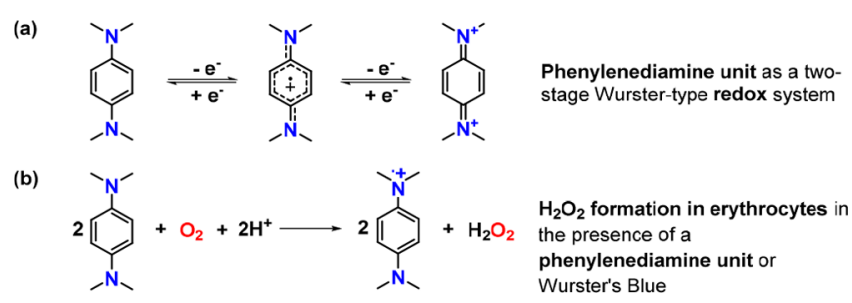

Figure 1. (a) $N, N, N^{\prime}, N^{\prime}$-Tetramethyl-p-phenylenediamine (TMPD) as a two-stage Wurster-type redox system. (b) Generation of hydrogen peroxide in erythrocytes in the presence of TMPD. ${ }^{23}$

enediamine units are found in several dyes and are relevant in several biological processes. In erythrocytes, they can react with molecular $\mathrm{O}_{2}$ to form superoxide radicals and Wurster salts, which can further react to generate hydrogen peroxide (Figure 1b). ${ }^{25}$ For example, $N, N, N^{\prime}, N^{\prime}$-tetramethyl- $p$-phenylenediamine (TMPD) undergoes autoxidation to generate "active oxygen" species which could be responsible for toxic changes in the erythrocytes. In a similar molecular system, Ito et al. reported one-electron oxidation of 9,10-bis( $\operatorname{di}(p$-anisyl)amino)anthracene inducing formation of a mixed-valence species, i.e., a delocalized cationic radical species, $[\mathrm{D}-\pi-$ $\mathrm{D}]^{\bullet+}{ }^{24}$ Recently, diarylamine scaffolds (derivatives of phenylenediamine) have been used for metal-free molecular photocatalytic fluoroalkylation. ${ }^{26}$ The diarylamine (donor) moiety acts as a strong reducing agent and promotes reduction. These studies encouraged us to design COFs based on diarylamine/ diaminobenzene units for exploiting their strong reduction properties in photocatalysis.

Herein, we report the synthesis of two highly crystalline COFs: TAPD- $(\mathrm{Me})_{2}$ and TAPD- $(\mathrm{OMe})_{2}$. Both COFs are highly stable (chemically and thermally) and form a Kagome lattice as a result of the $\mathrm{C} 4+\mathrm{C} 2$ linkage. There are only a limited number of COFs with Kagome lattices, ${ }^{27-29}$ and the $N, N, N^{\prime}, N^{\prime}$-tetrakis (4-aminophenyl)-1,4-phenylenediamine
(TAPD) linker expands the inventory of $\mathrm{C} 4$ linkers which can be used to form Kagome lattices. Considering the high charge transfer transitions in COFs, for the first time, TAPD- $(\mathrm{Me})_{2}$ and TAPD-(OMe $)_{2}$ COFs have been applied for photocatalytic production of $\mathrm{H}_{2} \mathrm{O}_{2}$ through oxygen reduction. This photocatalytic system is completely metal-free and green solvents are used for the reaction, thus paving way for a sustainable pathway.

\section{RESULTS AND DISCUSSION}

TAPD- $(\mathrm{Me})_{2}$ and TAPD-(OMe $)_{2} \mathrm{COF}$ are synthesized in the presence of $6 \mathrm{M}$ acetic acid $(0.1 \mathrm{~mL})$ by reacting $N, N, N^{\prime}, N^{\prime}$ tetrakis(4-aminophenyl)-1,4-phenylenediamine (TAPD, 23.6 mg. $0.5 \mathrm{mmol})$ with 2,5-dimethylbenzene-1,4-dicarboxaldehyde $\left((\mathrm{Me})_{2}, 16.2 \mathrm{mg}, 1 \mathrm{mmol}\right)$ or 2,5-dimethoxybenzene-1,4dicarboxaldehyde $\left((\mathrm{OMe})_{2}, 19.4 \mathrm{mg}, 1 \mathrm{mmol}\right)$, in the presence of $1: 1 \quad o$-dichlorobenzene/butanol $(0.6 \mathrm{~mL})$ or $1: 1$ dioxane/ mesitylene $(0.6 \mathrm{~mL})$ respectively (Figure 2 , section $\mathrm{S} 2$ in the Supporting Information). For the synthesis of the COFs, the TAPD linker was deliberately utilized because of the possibility of internal charge transfer transitions leading to strong absorption bands in the visible light region. In similar molecular systems (diarylamino(anthracene)), Konishi et al. showed that distorted donor planes induce interchromophoric conjugation rather than conjugation within the local structure which promotes charge transfer between the diarylamine and anthracene moieties. ${ }^{30}$ Contrary to the general expectation, Brédas et al. have shown that the strength of electronic interaction is higher in benzene than in anthracene for such diarylamino systems due to the dependence on steric interactions. ${ }^{31}$ This led us to use diarylamino(benzene) as the COF linker to promote strong electronic interactions.

The imine $(\mathrm{C}=\mathrm{N})$ bond formation was confirmed through Fourier transform infrared (FT-IR) spectroscopy. Stretching vibrations at 1616 and $1612 \mathrm{~cm}^{-1}$ correspond to imine linkages in TAPD- $(\mathrm{Me})_{2}$ and TAPD-(OMe $)_{2}$ COFs, respectively (Figures S4 and S5). ${ }^{1} \mathrm{H}$ direct excitation MAS NMR (35 $\mathrm{kHz}$ MAS; $800 \mathrm{MHz}$ ) confirmed the presence of phenyl, $\mathrm{N}=$ $\mathrm{CH}-\mathrm{Ph}$, and methyl and methoxy protons for TAPD-(Me $)_{2}$ and TAPD-(OMe $)_{2}$ COFs, respectively. ${ }^{13} \mathrm{C}\left\{{ }^{1} \mathrm{H}\right\}$ CPMAS (Figure $3 g-j$ ) revealed nine different carbon signals for TAPD$(\mathrm{Me})_{2} \mathrm{COF}$ and TAPD-(OMe $)_{2} \mathrm{COF}$. All carbon resonances can be assigned to the local chemical structure forming the Kagome sheets. Note that both ${ }^{1} \mathrm{H}$ MAS NMR and ${ }^{13} \mathrm{C}\left\{{ }^{1} \mathrm{H}\right\}$ CPMAS NMR reveal the presence of methoxy and methyl substitutions in the structure. Combining ${ }^{1} \mathrm{H}$ double quantum (DQ)-single quantum (SQ) and ${ }^{13} \mathrm{C}\left\{{ }^{1} \mathrm{H}\right\} \mathrm{CP}$ heterogeneous correlation (HETCOR) spectra allows confirmation of the local chemical environments occurring in the COF structures (Figure $3 \mathrm{c}-\mathrm{f}$ ). While ${ }^{13} \mathrm{C}\left\{{ }^{1} \mathrm{H}\right\} \quad \mathrm{CP}$ HETCOR reveals the substitution of the $C_{A}$ and $C_{B}$ of the phenyl moiety with methyl and methoxy groups, respectively, ${ }^{1} \mathrm{H}$ DQ-SQ MAS NMR reveals a strong correlation between the respective methyl/methoxy protons and the $\mathrm{HC} \alpha$ of the phenyl group (Figures S6-S9). Elemental analyses were performed to reveal the elemental composition of the COFs. The obtained $\mathrm{C} / \mathrm{N}$ and $\mathrm{C} / \mathrm{H}$ ratios were $7.23 / 13.49$ for TAPD- $(\mathrm{Me})_{2} \mathrm{COF}$ and $7.42 / 13.90$ for TAPD-(OMe $)_{2}$ COF, respectively. These values matched well with the theoretically calculated values (Table S2).

Powder X-ray diffraction (PXRD) analyses were performed to determine the structural features of the synthesized COFs. Both TAPD-(Me $)_{2}$ and TAPD-(OMe $)_{2}$ COFs exhibited 


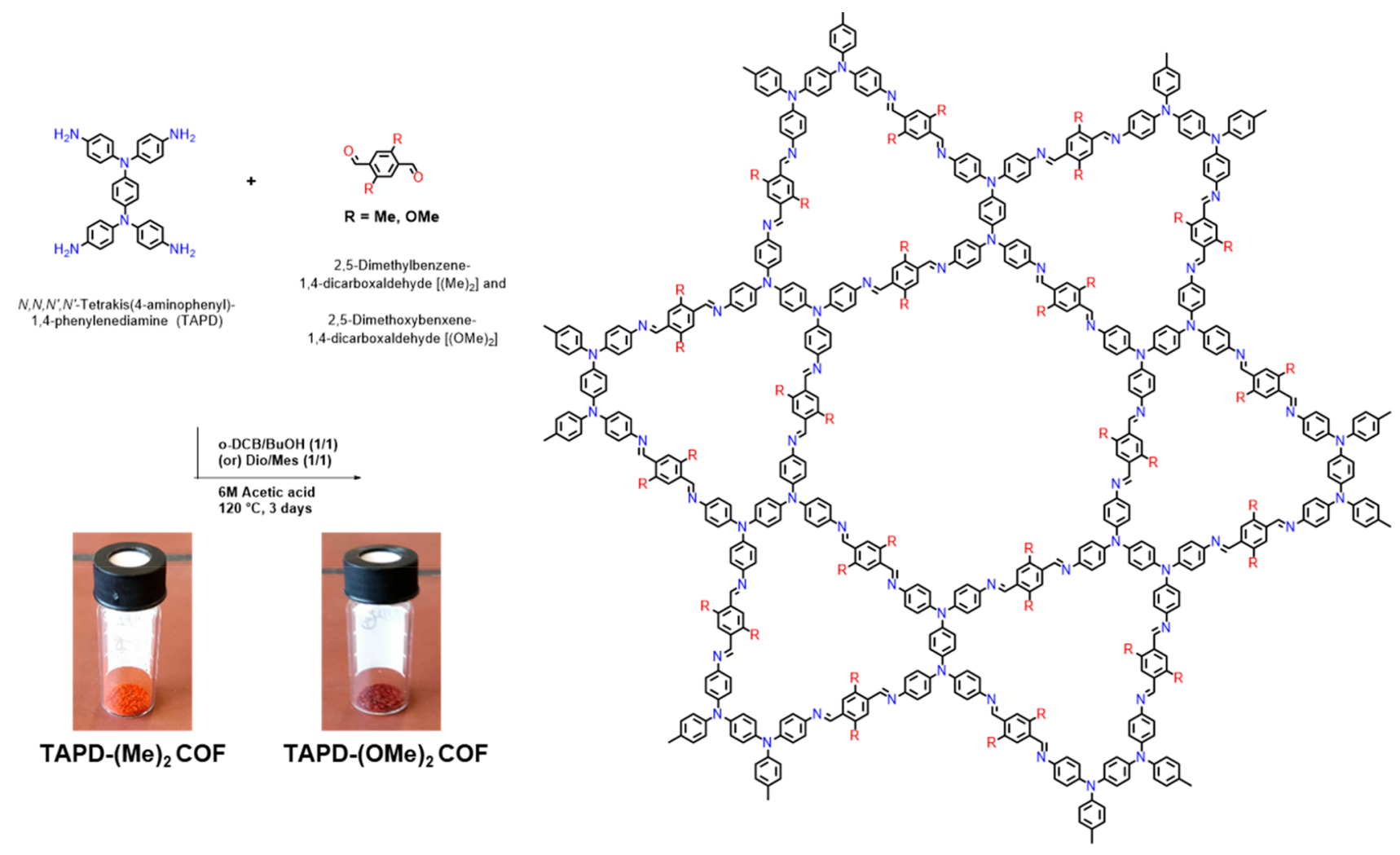

Figure 2. Synthesis of TAPD-(Me $)_{2}$ and TAPD- $(\mathrm{OMe})_{2} \mathrm{COFs}$ forming a dual pore Kagome lattice.

intense reflections in the low-angle region at 2.3 and $2.4^{\circ} 2 \theta(d$ spacing $\sim 3.8$ and $3.7 \mathrm{~nm}$ ), respectively. An additional set of lower symmetry reflections that could not be assigned to the starting monomers are also obtained in the low-angle region, indicating the formation of crystalline frameworks (Figure 4, Figures S21 and S24). Indexing of the PXRD patterns in primitive hexagonal lattices and the presence of broad diffraction peaks at $\sim 20.4$ and $18.6^{\circ} 2 \theta$ suggest the formation of a $2 \mathrm{D}$ layered material stacking in the $c$ direction through $\pi-\pi$ interactions. According to the symmetry of the linkers, the structural models for TAPD- $(\mathrm{Me})_{2}$ and TAPD-(OMe $)_{2}$ COFs were constructed by generating the expected $2 \mathrm{D}$ layers with kgm topology and modeling stacking sequences with eclipsed $(\mathrm{AA})$ and staggered $(\mathrm{AB})$ arrangement (Figure $4 \mathrm{c}-\mathrm{f}$, section S4 in the Supporting Information, Figures S21-S26). The models were geometrically optimized, and their corresponding theoretical PXRD patterns were compared to the experimentally measured patterns. Pawley fitting over the full profile was carried out to refine the final unit cell parameters (for TAPD$(\mathrm{Me})_{2}, a=b=43.26 \AA, c=4.35 \AA, R_{\mathrm{wp}}=3.28 \%$; for TAPD$\left.(\mathrm{OMe})_{2}, a=b=41.50 \AA, c=4.76 \AA, R_{\mathrm{wp}}=3.17 \%\right)$, resulting in low residual values and acceptable profile differences (Figure $4 a, b)$.

To further elucidate the atomic structure of the synthesized COFs, molecular dynamics (MD) simulations were performed at $300 \mathrm{~K}$ and 1 bar to include peak broadening effects. These MD results are obtained without fitting or refining any model parameter, using $a b$ initio derived force fields for the TAPD$(\mathrm{Me})_{2}$ and TAPD- $(\mathrm{OMe})_{2} \mathrm{COFs}$ with QuickFF protocol ${ }^{32,33}$ (section S5 in the Supporting Information). Furthermore, the dynamic simulations intrinsically take into account the movement of adjacent layers. Hence, no separate $A A$ and $A B$ models need to be considered. However, given that the functional groups in adjacent layers can be in either a parallel or an inverted conformation, both possibilities were explicitly modeled (Figure S28). As illustrated in Figure 5 and Figure S30, the MD simulations provide similar unit cell parameters for both COFs in line with the expectations for the almost identical building units used in both materials and indicate that the COFs display only limited deviations from a perfect AA stacking, showcasing the strong interlayer interactions. Furthermore, the MD simulations indicate that the most likely ordering of the functional groups is inverted for both COFs and allow the indexing of the experimentally observed PXRD peaks, as shown in Figure 5.

The permanent porosity of TAPD- $(\mathrm{Me})_{2} \mathrm{COF}$ and that of TAPD-(OMe $)_{2}$ COF were assessed by argon sorption measurements at $87 \mathrm{~K}$ and $\mathrm{N}_{2}$ sorption measurements at 77 $\mathrm{K}$ (Figure 6, Figures S32 and S33). Both COFs display a steep uptake in the low-pressure region $\left(P / P_{0}<0.01\right)$, corresponding to permanent microporosity. In addition, a step is observed in the isotherm around $P / P_{0}=0.22$. This feature represents the filling of the second type of bigger pores. The overall isotherm is a combination of type I and type IV isotherms, indicating both microporous and mesoporous characteristics as expected in the Kagome type structures. With the use of Ar sorption, Brunauer-Emmett-Teller (BET) surface area values of 1105 and $1165 \mathrm{~m}^{2} \cdot \mathrm{g}^{-1}$ were observed for TAPD- $(\mathrm{Me})_{2}$ and TAPD$(\mathrm{OMe})_{2} \mathrm{COFs}$, respectively. With the use of $\mathrm{N}_{2}$ sorption, the BET surface area values were calculated to be 1083 and 1153 $\mathrm{m}^{2} \cdot \mathrm{g}^{-1}$ for TAPD- $(\mathrm{Me})_{2}$ and TAPD-(OMe $)_{2}$ COFs, respectively. Pore size analysis, using an argon sorption-based quenched solid density functional theory (QSDFT) carbon kernel for cylindrical-type pores, shows two different pore sizes as expected from the Kagome type COF structures. The experimental and theoretical average pore sizes for TAPD- 

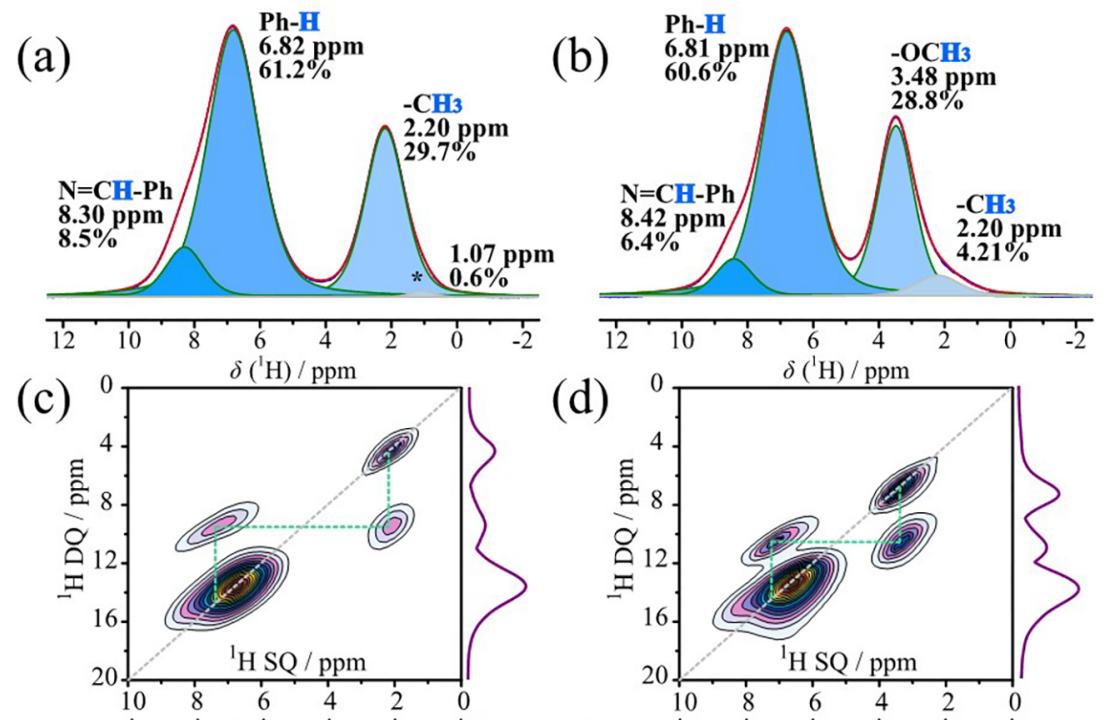

(d)
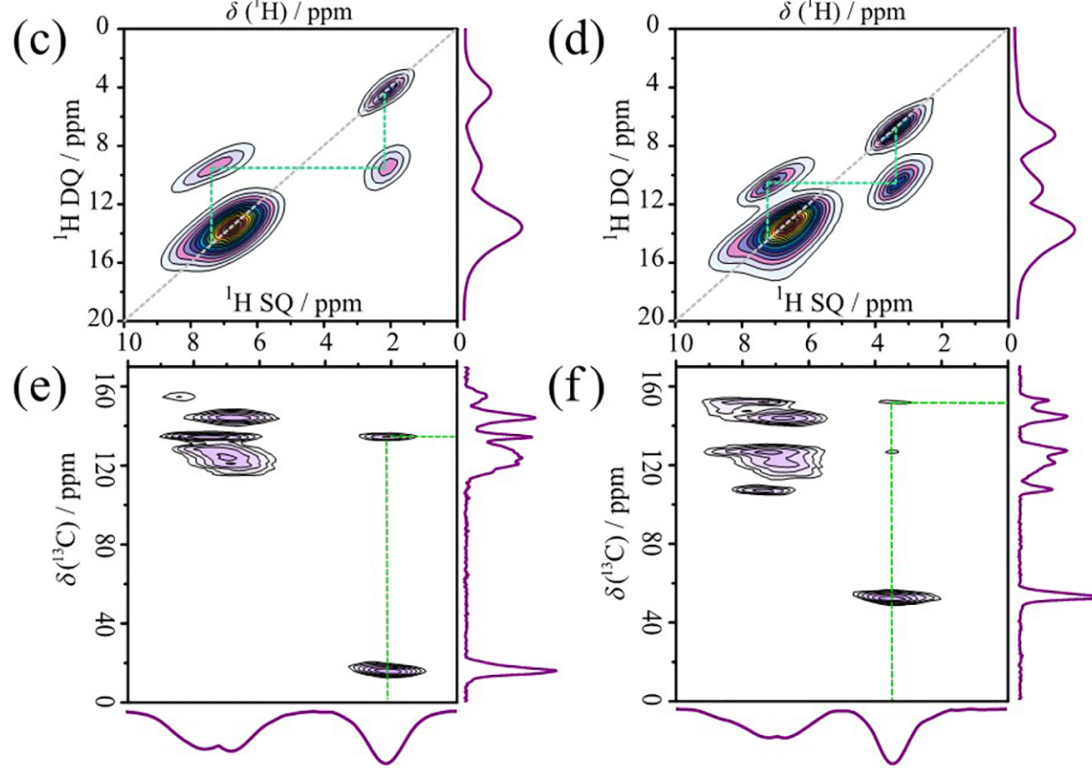

(f)
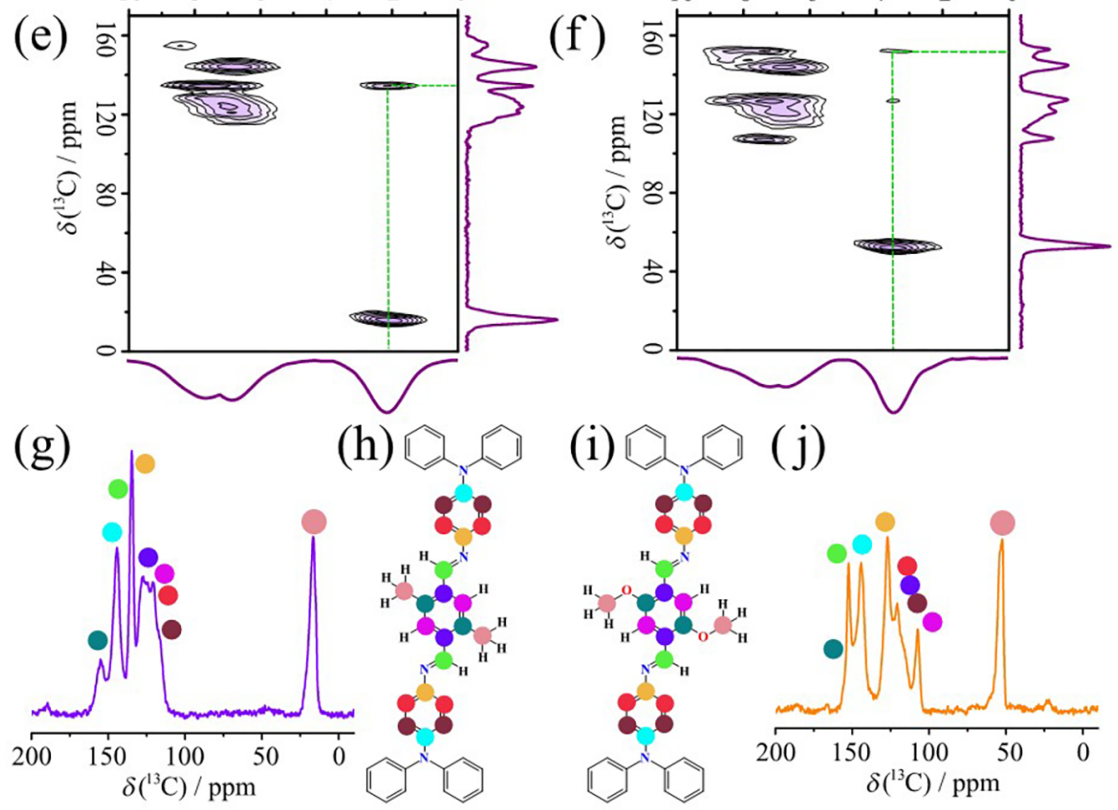

Figure 3. Solid-state NMR spectra of TAPD-(Me) ${ }_{2}$ (left column) and TAPD-(OMe) ${ }_{2}$ (right column). Panels a and b show ${ }^{1} \mathrm{H} \mathrm{MAS}(35 \mathrm{kHz})$ NMR spectra and decompositions which yielded the chemical shifts and fractions. Panels $\mathrm{c}$ and $\mathrm{d}$ show ${ }^{1} \mathrm{H}$ DQ-SQ $2 \mathrm{D}$ correlations indicating the proximity of one of the phenyl protons to the methyl and methoxy protons. Panels e and $\mathrm{f}$ show ${ }^{1} \mathrm{H}-{ }^{13} \mathrm{C}$ CP HETCOR $2 \mathrm{D}$ correlations indicating the proximity of one type of carbon atoms at the phenyl rings to the attached methyl and methoxy protons. The ${ }^{13} \mathrm{C}\left\{{ }^{1} \mathrm{H}\right\} \mathrm{CPMAS}$ spectrum $(\mathrm{g})$ corresponds to the structure $(\mathrm{h})$, and the spectrum $(\mathrm{j})$ corresponds to the structure (i). All the experiments were carried out on a Bruker Neo 800 $\mathrm{MHz}$ spectrometer operating at $18.8 \mathrm{~T}$ magnetic field.

$(\mathrm{Me})_{2}$ and TAPD-(OMe $)_{2} \mathrm{COFs}$ were $1.7 / 2.7 \mathrm{~nm}$ (theoretical $1.5 / 2.5 \mathrm{~nm}$ ) and $1.3 / 2.5 \mathrm{~nm}$ (theoretical $1.4 / 2.4 \mathrm{~nm}$ ), respectively (Figure 6, inset), thus confirming the formation of $2 \mathrm{D}$ layers with $\mathrm{kgm}$ topology stacking in an eclipsed AA stacking mode. These characterizations prove the successful formation of the expected structures of TAPD-(Me $)_{2}$ and TAPD- $(\mathrm{OMe})_{2}$ COFs.

Transmission electron microscopy (TEM) images of both COFs revealed crystalline features with domain sizes in the range of $>50 \mathrm{~nm}$ (Figure 7a,c, Figures S14 and S16). Scanning electron microscopy (SEM) analyses show rough spherical morphologies of both COFs (Figure 7b,d, Figures S15 and S17). To analyze the structural integrity, the chemical and thermal stabilities of the COFs were tested. Both COFs (20 mg each) were immersed in $1 \mathrm{M} \mathrm{HCl}$ (acidic) and $1 \mathrm{M} \mathrm{NaOH}$ (basic) solutions for $72 \mathrm{~h}$ and were washed with water and acetone before further analysis. PXRD patterns collected after these treatments show that the COFs retain their crystallinities and remain stable (Figures S18 and S19). The yields of the COFs after treatment with acid and base were $>90 \%$. Additionally, both COFs remain insoluble in common organic solvents such as acetone, methanol, ethanol, hexane, tetrahydrofuran, diethyl ether, and dichloromethane. Furthermore, after the COFs were soaked in dimethylformamide for 8 days, the crystallinity was retained (Figures S18 and S19). In addition to the chemical stability, no significant loss in mass of COFs was observed when they were heated to $450{ }^{\circ} \mathrm{C}$ as shown through thermogravimetric analyses (Figure S20).

By integrating functionalized units or groups such as triazine, ${ }^{2}$ diacetylene, ${ }^{9}$ sulfone, ${ }^{34}$ etc., in the COF backbone, 

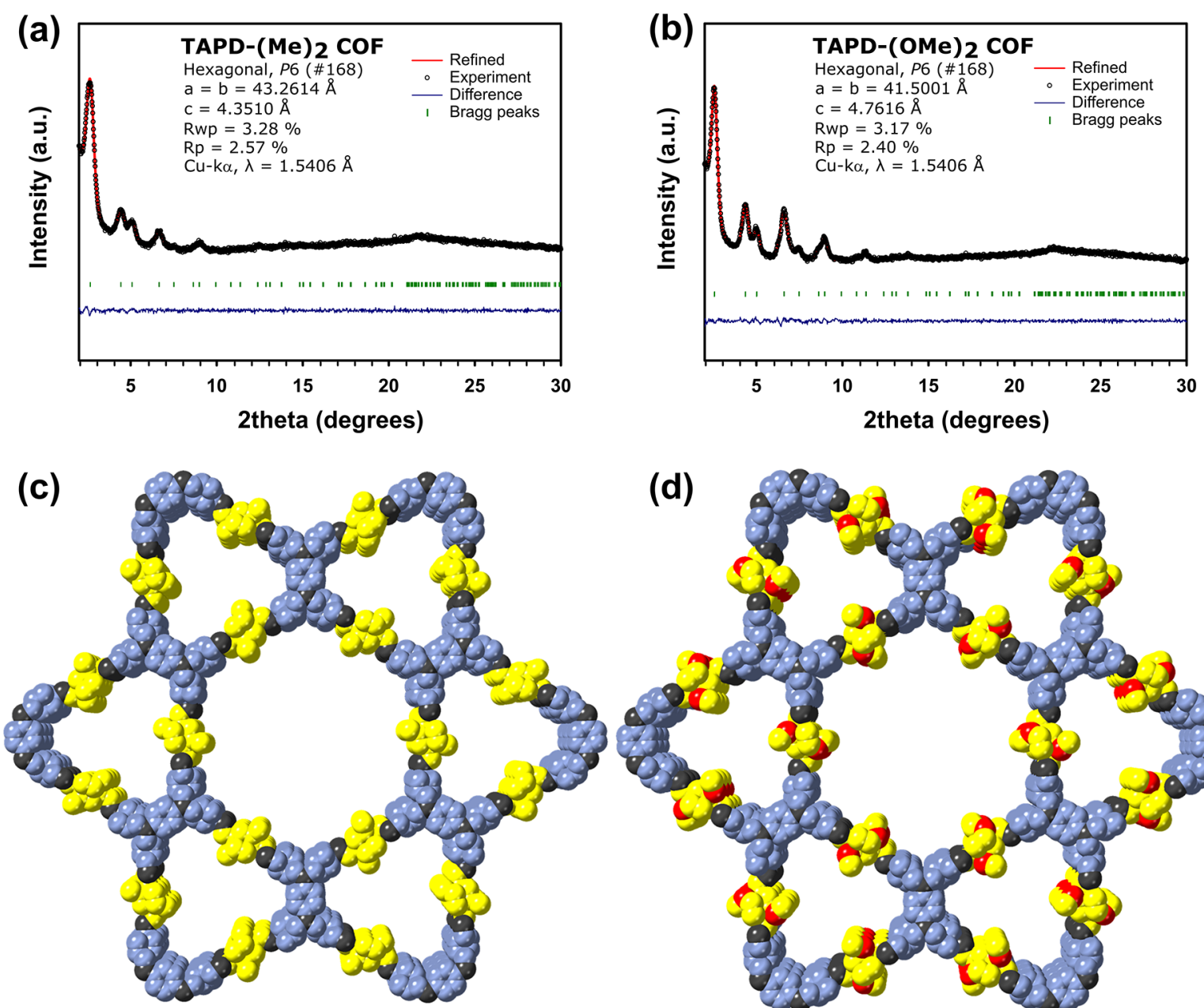

(e)

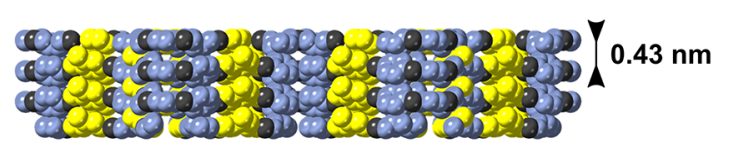

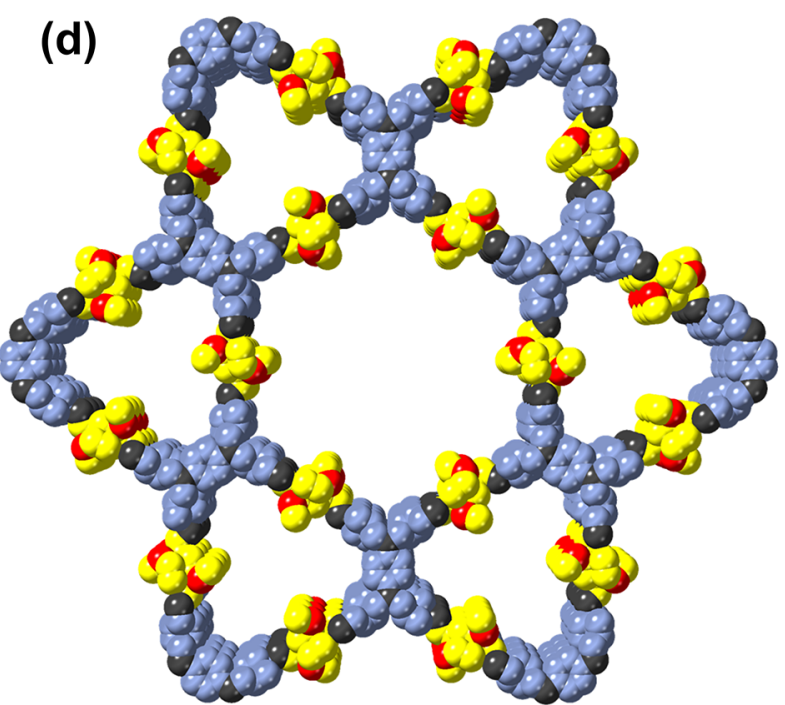

(f)

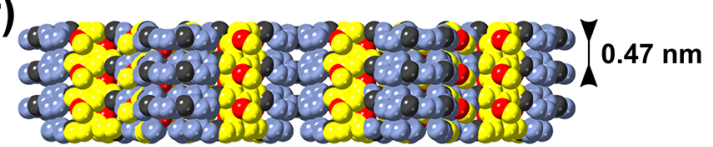

Figure 4. PXRD pattern and Pawley refinement of (a) TAPD-(Me $)_{2}$ and (b) TAPD-(OMe $)_{2}$ COFs. Top views of (c) TAPD-(Me) $)_{2}$ and (d) TAPD- $(\mathrm{OMe})_{2}$ COFs showing the ideal eclipsed (AA) structures. Side views of (e) TAPD-(Me $)_{2}$ and (f) TAPD-(OMe $)_{2}$ COFs. H atoms are omitted for clarity.
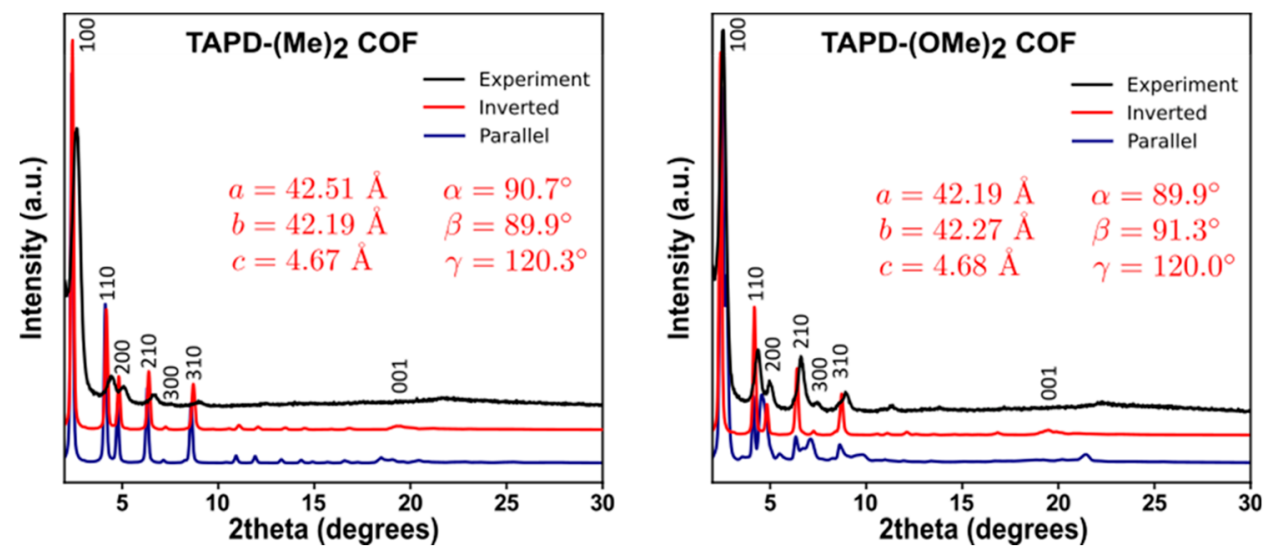

Figure 5. Comparison between experimentally observed and MD calculated PXRD patterns for TAPD-(Me $)_{2}$ and TAPD-(OMe $)_{2}$, averaged over the course of a $400 \mathrm{ps} \mathrm{MD}$ simulation at $300 \mathrm{~K}$ and $1 \mathrm{bar}(\mathrm{Cu}-\mathrm{k} \alpha, \lambda=1.5406 \AA)$ using $a b$ initio derived system-specific force fields. The resulting unit cell parameters and peak positions have been indicated.

several photocatalytic conversions have been achieved successfully. For efficient photocatalytic activity, the COF needs to generate electron-hole pairs and avoid recombination. The (diarylamino)benzene unit in the TAPD- $(\mathrm{Me})_{2}$ and 


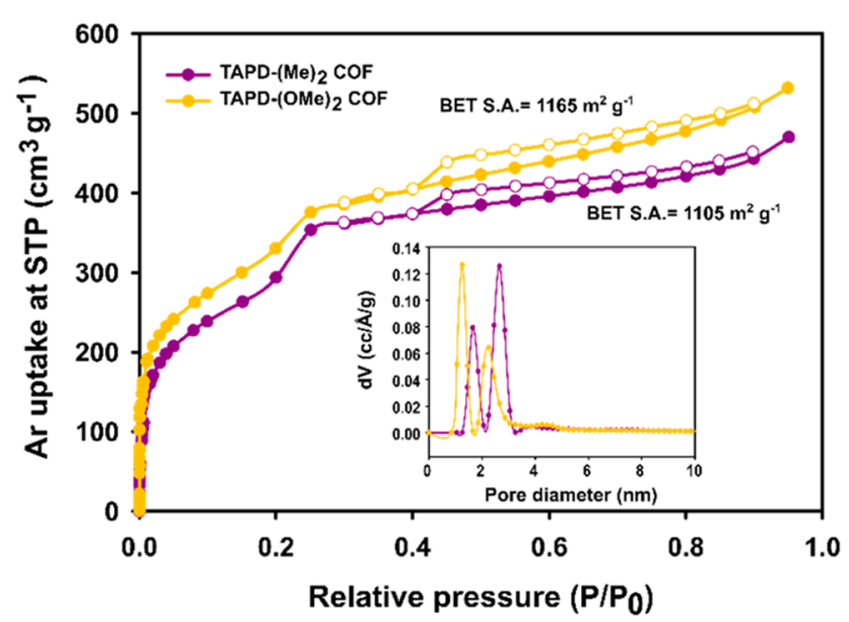

Figure 6. Ar sorption isotherms and pore size distributions (inset) of TAPD-(Me $)_{2}$ COF and TAPD-(OMe $)_{2}$ COF.

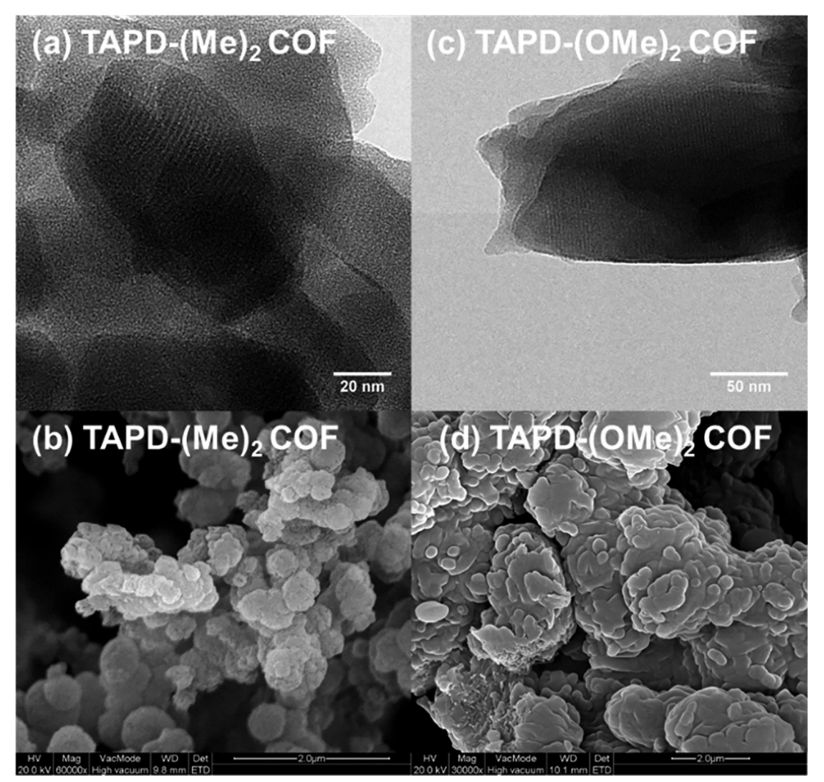

Figure 7. TEM and SEM images of ( $a, b)$ TAPD- $(\mathrm{Me})_{2}$ and $(c, d)$ TAPD-(OMe $)_{2}$ COFs showing crystalline domains and the morphology of COF crystallites.

TAPD-(OMe $)_{2}$ COFs is a strong donor and has strong reducing properties. ${ }^{26}$ Moreover, high crystallinity of the COFs can enhance the charge transfer kinetics. ${ }^{34}$ Diffuse reflectance ultraviolet-visible (UV-vis) spectroscopy was used to analyze the optical properties of the COFs, where it was observed that each COF exhibits a broad and strong absorbance peak in the visible region (Figure 8a). The optical band gaps calculated from Tauc plots are 2.61 and $2.63 \mathrm{eV}$, respectively, for TAPD$(\mathrm{Me})_{2}$ and TAPD-(OMe $)_{2}$ COFs (Figure $8 b$ ). This makes them ideal materials for visible light activation and photocatalytic $\mathrm{H}_{2} \mathrm{O}_{2}$ generation.

The positions of the conduction bands (CBs) and valence bands (VBs) of both COFs were estimated on the basis of linear sweep voltammetry measurements under chopped illumination. $^{35,36}$ A photocatalyst-coated FTO substrate was used as the working electrode in a three-electrode setup, together with an $\mathrm{Ag} / \mathrm{AgCl}(3 \mathrm{M} \mathrm{NaCl})$ reference electrode and a Pt coil counter electrode. Under an applied bias of $+0.4 \mathrm{~V}$ vs $\mathrm{Ag} / \mathrm{AgCl}$ and chopped white light illumination, an anodic photocurrent was measured. As the bias voltage was swept in the negative direction from +0.4 to $-0.4 \mathrm{~V}$ at a scan rate of 4 $\mathrm{mV} / \mathrm{s}$, the photocurrent decreased in magnitude and then changed sign. The potential at which the sign change of the photocurrent occurred allows calculation of a good estimate of the conduction band minimum (Figures S35-S37). The CB band positions were determined in three different alkaline buffers, displaying a Nernstian dependence of the $\mathrm{CB}$ position with $\mathrm{pH}$. From these values, the $\mathrm{CB}$ positions at $\mathrm{pH} 0$ were extrapolated (Figure S38). In combination with the optical band gaps as derived from the Tauc plots, the band structures were derived for TAPD- $(\mathrm{Me})_{2}(\mathrm{CB}=-0.97 \mathrm{eV}, \mathrm{VB}=1.64$ $\mathrm{eV})$ and TAPD- $(\mathrm{OMe})_{2}(\mathrm{CB}=-0.80 \mathrm{eV}, \mathrm{VB}=1.83 \mathrm{eV})$ $\mathrm{COFs}$ as shown in Figure 8c. The band positions are very much under the requirements for oxygen reduction to hydrogen peroxide $(0.68 \mathrm{~V}$ vs $\mathrm{NHE})$; hence the $\mathrm{COFs}$ were utilized further for $\mathrm{H}_{2} \mathrm{O}_{2}$ generation.

Photocatalytic $\mathrm{H}_{2} \mathrm{O}_{2}$ generation experiments were performed in sealed glass vials with water:ethanol (9:1), where ethanol acts as the electron and proton donor. Under visible light $(420-700 \mathrm{~nm})$ irradiation, long-term $(16 \mathrm{~h})$ reactions were carried out at room temperature (condenser) with $20 \mathrm{mg}$ of $\mathrm{COF}$ used as the photocatalyst. $\mathrm{H}_{2} \mathrm{O}_{2}$ concentration was determined through iodometric titration. ${ }^{44}$ After $16 \mathrm{~h}$ of reaction, the TAPD- $(\mathrm{Me})_{2}$ and TAPD- $(\mathrm{OMe})_{2}$ COFs produced 25.3 and $22.6 \mu \mathrm{mol}$ of $\mathrm{H}_{2} \mathrm{O}_{2}$, respectively, when irradiated under $250 \mathrm{~W}\left(5.46 \mathrm{~W} \mathrm{~m}^{-2}\right)$ light. This is quite comparable to pure carbon nitride, which produced $30 \mu \mathrm{mol}$ of $\mathrm{H}_{2} \mathrm{O}_{2}$ but used a $2 \mathrm{~kW}\left(26.9 \mathrm{~W} \mathrm{~m}^{-2}\right)$ light source and with 9 times higher ethanol content. ${ }^{22}$ Also, in the case of TAPD$(\mathrm{Me})_{2} \mathrm{COF}$ when a higher amount of ethanol (water:ethanol 1:9) was used, $57.2 \mu \mathrm{mol}$ of $\mathrm{H}_{2} \mathrm{O}_{2}$ was produced, which is almost twice more than pure carbon nitride. ${ }^{22}$ We acknowledge that it is difficult to compare the activities of different materials due to different reaction conditions (irradiation wavelength, light intensity, sacrificial agent, reaction time, etc.). Besides, most of the catalysts used in the literature (Table 1 ) for $\mathrm{H}_{2} \mathrm{O}_{2}$ production involve the assistance of a metal ( $\mathrm{Au}$, $\mathrm{TiO}_{2}$, etc.), whereas the COFs provide a completely metal-free platform. The $\mathrm{H}_{2} \mathrm{O}_{2}$ production vs time profile was recorded for the photocatalytic reaction over $5 \mathrm{~h}$ (Figure $8 \mathrm{~d}$ ). The overall $\mathrm{H}_{2} \mathrm{O}_{2}$ production rates of $97 \pm 10$ and $91 \pm 10 \mu \mathrm{mol}$ $\mathrm{h}^{-1} \mathrm{~g}_{\text {cat }}{ }^{-1}$ were obtained for TAPD-(Me $)_{2}$ and TAPD- $(\mathrm{OMe})_{2}$ COFs, respectively.

The following reaction mechanism is proposed (Figure S39). The reaction proceeds with the formation of electronhole carriers through visible light irradiation on the COF. The holes are utilized by ethanol to produce acetaldehyde and two protons along with it. Molecular oxygen utilizes the electrons from the $\mathrm{COF}$ and the protons from the alcohol transformation to produce $\mathrm{H}_{2} \mathrm{O}_{2}$. Electron and hole trapping experiments were performed using silver nitrate $\left(\mathrm{AgNO}_{3}\right)$ and triethylamine (TEA), respectively (Table S3). In the case of the electron trapping experiment there was a drastic decrease in the formation of $\mathrm{H}_{2} \mathrm{O}_{2}$, whereas in the case of the hole trapping experiment there was no formation of $\mathrm{H}_{2} \mathrm{O}_{2}$. This emphasizes the role of photocatalytic electron-hole carriers in the overall reaction. Further, benzoquinone was used as a radical scavenger in the reaction system to determine the role of radicals in the reaction (Table S3). However, the reaction proceeded without much hindrance which means the radicals formed are quickly utilized for the formation of $\mathrm{H}_{2} \mathrm{O}_{2}$. A similar fast step was also observed in the carbon nitride 
(a)

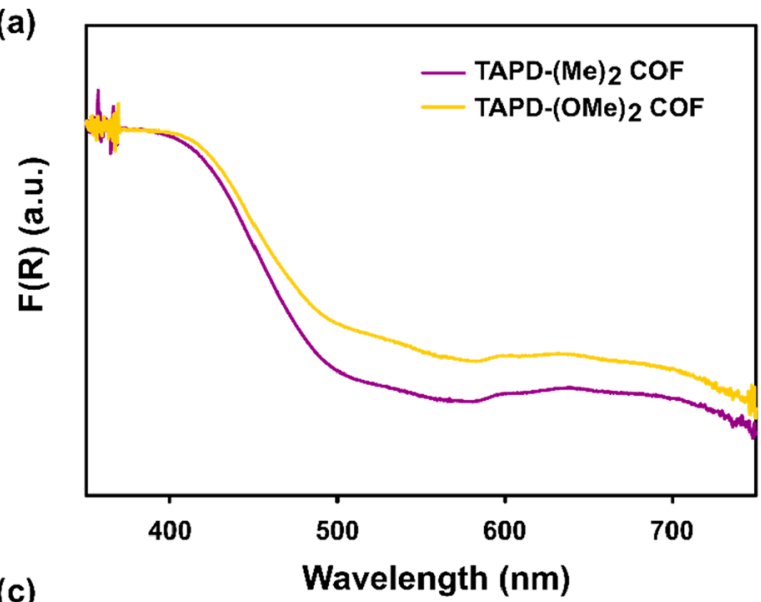

(c)

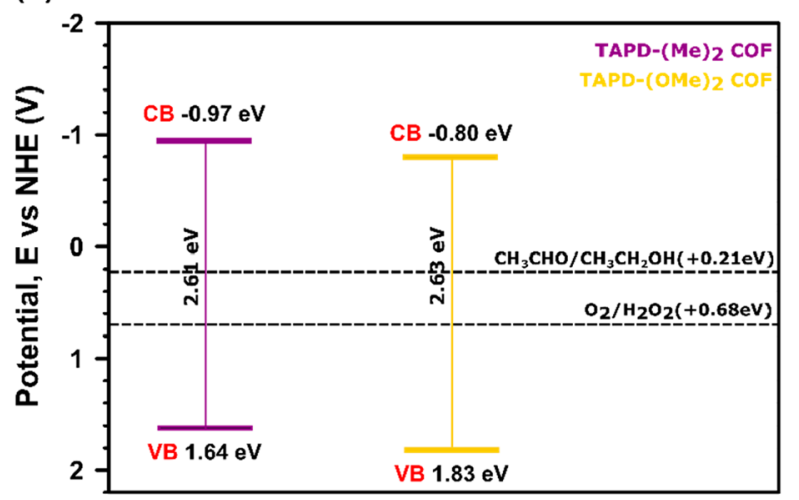

(b)
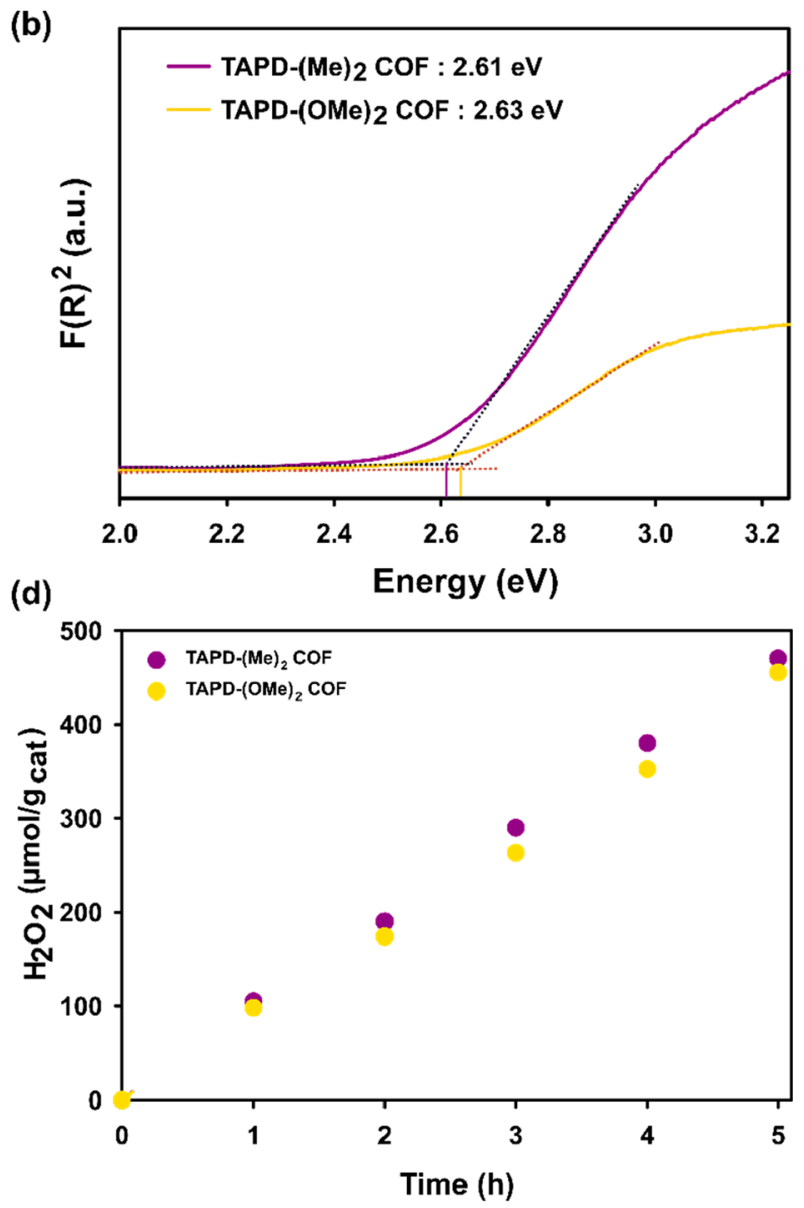

Figure 8. (a) Solid state UV-vis spectra, (b) Tauc plot analyses for band gap calculations, (c) band potential alignments of the COF vs NHE (V) at $\mathrm{pH}$, and (d) $\mathrm{H}_{2} \mathrm{O}_{2}$ production per gram of catalyst over $5 \mathrm{~h}$ of reaction time of TAPD- $(\mathrm{Me})_{2}$ and TAPD-(OMe $)_{2} \mathrm{COFs}$.

Table 1. Photocatalytic Production of $\mathrm{H}_{2} \mathrm{O}_{2}$

\begin{tabular}{|c|c|c|c|c|c|}
\hline entry & material & $\mathrm{H}_{2} \mathrm{O}_{2}$ production rate & irradiation conditions & solvent system & reference \\
\hline 1 & g- $\mathrm{C}_{3} \mathrm{~N}_{4}$ & $63.00 \mu \mathrm{mol} \mathrm{h}^{-1} \mathrm{~g}_{\mathrm{cat}}{ }^{-1}$ & $\lambda=420-500 \mathrm{~nm}$ & $\mathrm{H}_{2} \mathrm{O}: \mathrm{EtOH}(1: 9)$ & 22 \\
\hline 2 & $\mathrm{~g}-\mathrm{C}_{3} \mathrm{~N}_{4} /$ PDI-BN0.2-rGO ${ }_{0.05}$ & $30.80 \mu \mathrm{mol} \mathrm{h}^{-1} \mathrm{~g}_{\text {cat }}{ }^{-1}$ & $\lambda>420 \mathrm{~nm}$ & $\mathrm{H}_{2} \mathrm{O}$ & 37 \\
\hline 3 & $\mathrm{PEI} / \mathrm{C}_{3} \mathrm{~N}_{4}$ & $208.10 \mu \mathrm{mol} \mathrm{h}^{-1} \mathrm{~g}_{\mathrm{cat}}{ }^{-1}$ & $\begin{array}{l}\text { solar simulator } \\
(\mathrm{AM}=1.5)\end{array}$ & $\mathrm{H}_{2} \mathrm{O}$ & 38 \\
\hline 4 & $\mathrm{Si} / \mathrm{TiO}_{2}-\mathrm{Au}$ & $14.80 \mu \mathrm{mol} \mathrm{h}^{-1}$ & $\lambda=365 \mathrm{~nm}$ & $\begin{array}{l}0.01 \mathrm{M} \mathrm{HCl}, \mathrm{Y}^{3+} \\
\text { cocatalyst }\end{array}$ & 39 \\
\hline 5 & $\mathrm{~g}-\mathrm{C}_{3} \mathrm{~N}_{4} / \mathrm{AQ}-\mathrm{COOH}$ & $361.00 \mu \mathrm{mol} \mathrm{h}^{-1} \mathrm{~g}_{\text {cat }}^{-1}$ & $\lambda>400 \mathrm{~nm}$ & propan-2-ol/ $\mathrm{H}_{2} \mathrm{O}(1: 9)$ & 40 \\
\hline 6 & $\mathrm{~g}-\mathrm{C}_{3} \mathrm{~N}_{4} / \mathrm{rGO}(10 \mathrm{wt} \%)$ & $74.30 \mu \mathrm{mol} \mathrm{h}^{-1} \mathrm{~g}_{\mathrm{cat}}^{-1}$ & $\lambda>400 \mathrm{~nm}$ & propan-2-ol/ $\mathrm{H}_{2} \mathrm{O}(1: 9)$ & 40 \\
\hline 7 & $\begin{array}{l}\text { boron nitride quantum } \\
\text { dots-carbon nitride (BNQD/UPCN) }\end{array}$ & $72.30 \mu \mathrm{mol} \mathrm{h}^{-1} \mathrm{~g}_{\mathrm{cat}}^{-1}$ & $\lambda>420 \mathrm{~nm}$ & propan-2-ol/ $\mathrm{H}_{2} \mathrm{O}(1: 9)$ & 41 \\
\hline 8 & $\mathrm{C}-\mathrm{N}-\mathrm{g}-\mathrm{C}_{3} \mathrm{~N}_{4}$ & $0.98 \mu \mathrm{mol} \mathrm{h}^{-1} \mathrm{~g}_{\mathrm{cat}}^{-1}$ & $420<\lambda<700 \mathrm{~nm}$ & $\mathrm{H}_{2} \mathrm{O}$ & 42 \\
\hline 9 & $\mathrm{OPA} / \mathrm{Zr}_{92.5} \mathrm{Ti}_{7.5}-\mathrm{MOF}$ & $9700.00 \mu \mathrm{mol} \mathrm{L}^{-1} \mathrm{~h}^{-1}$ & $\lambda>420 \mathrm{~nm}$ & $\begin{array}{l}\text { benzyl } \\
\quad \text { alcohol: } \mathrm{H}_{2} \mathrm{O}(2.5: 1)\end{array}$ & 20 \\
\hline 10 & resorcinol-formaldehyde resins & $\sim 40.00^{a} \mu \mathrm{mol} \mathrm{h}^{-1}$ & $\lambda>420 \mathrm{~nm}$ & $\mathrm{H}_{2} \mathrm{O}$ & 43 \\
\hline 11 & TAPD- $(\mathrm{Me})_{2} \mathrm{COF}$ & $97.00 \mu \mathrm{mol} \mathrm{h}^{-1} \mathrm{~g}_{\mathrm{cat}}^{-1}$ & $\lambda=420-700 \mathrm{~nm}$ & $\mathrm{H}_{2} \mathrm{O}: \mathrm{EtOH}(9: 1)$ & this work \\
\hline 12 & TAPD- $(\mathrm{OMe})_{2} \mathrm{COF}$ & $91.00 \mu \mathrm{mol} \mathrm{h}^{-1} \mathrm{~g}_{\mathrm{cat}}{ }^{-1}$ & $\lambda=420-700 \mathrm{~nm}$ & $\mathrm{H}_{2} \mathrm{O}: \mathrm{EtOH}(9: 1)$ & this work \\
\hline 13 & $\mathrm{TAPD}-(\mathrm{Me})_{2} \mathrm{COF}$ & $234.52 \mu \mathrm{mol} \mathrm{h}^{-1} \mathrm{~g}_{\mathrm{cat}}^{-1}$ & $\lambda=420-700 \mathrm{~nm}$ & $\mathrm{H}_{2} \mathrm{O}: \mathrm{EtOH}(1: 9)$ & this work \\
\hline
\end{tabular}

photocatalyst, $^{22}$ where the one-electron reduction of $\mathrm{O}_{2}$ to release superoxide $\left({ }^{\bullet} \mathrm{OOH}\right)$ is suppressed. To determine the $\mathrm{H}_{2} \mathrm{O}_{2}$ selectivity, the reaction was tested with benzyl alcohol as the proton source instead of ethanol, as the quantification of benzaldehyde is more reliable than that of acetaldehyde using NMR analysis. The reaction was performed with water:benzyl alcohol $(1: 9)$ for $16 \mathrm{~h}$ at room temperature by using TAPD-
(Me $)_{2}$ COF. A $53.7 \mu$ mol amount of $\mathrm{H}_{2} \mathrm{O}_{2}$ was produced, which is comparable to the reaction with ethanol under the same conditions. ${ }^{1} \mathrm{H}$ NMR analysis showed the production of benzaldehyde, and correspondingly $\mathrm{H}_{2} \mathrm{O}_{2}$ was produced with 96\% selectivity (Figure S40). In addition, this also confirms the mechanism of the reaction. As expected, alcohol to aldehyde conversion occurs which provides protons for reducing oxygen 
to $\mathrm{H}_{2} \mathrm{O}_{2}$. A control reaction was performed with all substrates excluding the COF yielding no significant amount of $\mathrm{H}_{2} \mathrm{O}_{2}$. Further, the reaction was also tested with all the substrates and the $\mathrm{COF}$ but in the absence of light. $\mathrm{No}_{2} \mathrm{O}_{2}$ was produced, thus confirming the requirement of light (Table S3). To check the reusability of the catalyst, the reaction was performed for five consecutive cycles with TAPD-(Me $)_{2} \mathrm{COF}$ and no significant loss of activity was observed (Figure S41). The PXRD patterns of the COFs after $16 \mathrm{~h}$ of photocatalytic reactions show that they retain crystallinity, confirming that the structure is stable under the reaction conditions (Figures S42 and S43). SEM analyses before and after catalysis of TAPD$(\mathrm{Me})_{2}$ and TAPD-(OMe $)_{2}$ COFs show no changes in the overall morphologies (Figures S44 and S45). Additionally, the reaction was performed for $96 \mathrm{~h}$ continuously and $142.3 \mu \mathrm{mol}$ of $\mathrm{H}_{2} \mathrm{O}_{2}$ was obtained. The production was still linear compared to the overall kinetics in the short-term reactions (Figure S46). The effect of different alcohol sources in the reaction was tested by performing the photocatalytic reactions using isopropanol and methanol in addition to ethanol and benzyl alcohol. The production of $\mathrm{H}_{2} \mathrm{O}_{2}$ was in the order isopropanol $>$ ethanol $>$ methanol $>$ benzyl alcohol (Figure S47). These results imply that the COFs are active for metalfree visible light photocatalytic production of $\mathrm{H}_{2} \mathrm{O}_{2}$ by oxygen reduction.

\section{CONCLUSION}

Inspired by Wurster-type systems, we have synthesized a new series of imine COFs consisting of (diarylamino)benzene units. These COFs are highly crystalline and arrange into a Kagome lattice. ${ }^{13} \mathrm{C}-{ }^{1} \mathrm{H}$ and ${ }^{1} \mathrm{H}-{ }^{1} \mathrm{H}$ NMR experiments confirmed the local chemical environments of the COFs. The COFs remained stable under various thermochemical conditions. Molecular dynamics simulations on the COF structures further confirmed the AA stacked crystalline nature. Both COFs displayed high surface areas, strong absorption in the visible light region, and ideal band gaps for photocatalysis. The absolute positions of the conduction and valence bands were determined by linear sweep voltammetry under chopped illumination. Photocatalytic reactions using oxygen-saturated water under visible light irradiation showed a high $\mathrm{H}_{2} \mathrm{O}_{2}$ production rate. The catalysts are stable and reusable for several runs of the reaction. This study is the first example of utilizing COFs for photocatalytic $\mathrm{H}_{2} \mathrm{O}_{2}$ production and opens a new avenue toward solar driven metal-free photocatalysis.

\section{ASSOCIATED CONTENT}

\section{SI Supporting Information}

The Supporting Information is available free of charge at https://pubs.acs.org/doi/10.1021/jacs.0c09684.

Experimental details on organic synthesis, NMR, FT-IR, elemental analyses, TEM, SEM, structural modeling, $a b$ initio PXRD modeling, photo(electro)chemical characterization, catalytic evaluations, and stability tests (PDF)

Crystal structure data of TAPD-(Me $)_{2} \mathrm{COF}$ with Pawley refinement (CIF)

Crystal structure data of TAPD- $(\mathrm{OMe})_{2} \mathrm{COF}$ with Pawley refinement (CIF)

Force fields (ZIP)

\section{AUTHOR INFORMATION}

\section{Corresponding Authors}

Pascal Van Der Voort - COMOC - Center for Ordered Materials, Organometallics and Catalysis, Department of Chemistry, Ghent University, 9000 Ghent, Belgium; (1) orcid.org/0000-0002-4874-0943;

Email: pascal.vandervoort@ugent.be

Arne Thomas - Department of Chemistry/Functional Materials, Technische Universität Berlin, 10623 Berlin, Germany; 이잉.org/0000-0002-2130-4930;

Email: arne.thomas@tu-berlin.be

\section{Authors}

Chidharth Krishnaraj - COMOC - Center for Ordered Materials, Organometallics and Catalysis, Department of Chemistry, Ghent University, 9000 Ghent, Belgium; Department of Chemistry/Functional Materials, Technische Universität Berlin, 10623 Berlin, Germany; ○orcid.org/ 0000-0001-8625-7322

Himanshu Sekhar Jena - COMOC - Center for Ordered Materials, Organometallics and Catalysis, Department of Chemistry, Ghent University, 9000 Ghent, Belgium; (1) orcid.org/0000-0002-5869-5226

Laurens Bourda - COMOC - Center for Ordered Materials, Organometallics and Catalysis, Department of Chemistry and XStruct - Bio-Inorganic Chemistry, Department of Chemistry, Ghent University, 9000 Ghent, Belgium

Andreas Laemont - COMOC - Center for Ordered Materials, Organometallics and Catalysis, Department of Chemistry, Ghent University, 9000 Ghent, Belgium

Pradip Pachfule - Department of Chemistry/Functional Materials, Technische Universität Berlin, 10623 Berlin, Germany

Jérôme Roeser - Department of Chemistry/Functional Materials, Technische Universität Berlin, 10623 Berlin, Germany

C. Vinod Chandran - NMRCoRe, 3001 Leuven, Belgium; Center for Surface Chemistry and Catalysis Characterisation and Application Team (COK-kat), Department of Microbial and Molecular Systems (M2S), KU Leuven, 3001 Leuven, Belgium

Sander Borgmans - Center for Molecular Modeling (CMM), Ghent University, B-9052 Zwijnaarde, Belgium

Sven M. J. Rogge - Center for Molecular Modeling (CMM), Ghent University, B-9052 Zwijnaarde, Belgium; (1) orcid.org/0000-0003-4493-5708

Karen Leus - COMOC - Center for Ordered Materials, Organometallics and Catalysis, Department of Chemistry, Ghent University, 9000 Ghent, Belgium

Christian V. Stevens - Synthesis, Bioresources and Bioorganic Chemistry Research Group (SynBioC), Department of Green Chemistry and Technology, Ghent University, 9000 Ghent, Belgium; (1) orcid.org/0000-0003-4393-5327

Johan A. Martens - NMRCoRe, 3001 Leuven, Belgium; Center for Surface Chemistry and Catalysis Characterisation and Application Team (COK-kat), Department of Microbial and Molecular Systems (M2S), KU Leuven, 3001 Leuven, Belgium

Veronique Van Speybroeck - Center for Molecular Modeling (CMM), Ghent University, B-9052 Zwijnaarde, Belgium; (1) orcid.org/0000-0003-2206-178X

Eric Breynaert - NMRCoRe, 3001 Leuven, Belgium; Center for Surface Chemistry and Catalysis - Characterisation and 
Application Team (COK-kat), Department of Microbial and Molecular Systems (M2S), KU Leuven, 3001 Leuven, Belgium

Complete contact information is available at: https://pubs.acs.org/10.1021/jacs.0c09684

\section{Author Contributions}

All authors have given approval to the final version of the manuscript.

\section{Notes}

The authors declare no competing financial interest.

\section{ACKNOWLEDGMENTS}

The authors thank Katrien Haustraete for the TEM measurements. C.K., S.B., P.V.D.V., V.V.S., and C.V.S. thank the Research Board of Ghent University (GOA010-17, BOF GOA2017000303) for funding. C.K. acknowledges the support from the FWO travel abroad grant V427919N. H.S.J. thanks FWO [PEGASUS $]^{2}$ Marie Sklodowska-Curie grant agreement No. 665501 for Incoming postdoctoral fellowship. S.M.J.R. wishes to thank the Fund for Scientific Research Flanders (FWO) for a postdoctoral fellowship (Grant No. 12T3519N). This work was supported by the Hercules Foundation (AKUL/13/21) and by the Flemish Government, department EWI, via the Hermes Fund (AH.2016.134). J.A.M. and P.V.D.V. acknowledge VLAIO for Moonshot funding (ARCLATH, $\mathrm{n}^{\circ}$ HBC.2019.0110). J.A.M. acknowledges the Flemish Government for long-term structural funding (Methusalem Beneficiary Johan A. Martens). J.A.M. and V.V.S. have received funding from the European Research Council (ERC) under the European Union's Horizon 2020 research and innovation program under Grant Agreement Nos. 834134 and 647755 (DYNPOR), respectively. A.T., P.P., and J.R. acknowledge the funding by the Deutsche Forschungsgemeinschaft (DFG, German Research Foundation) under Germany's Excellence Strategy-EXC 2008-390540038UniSysCat and the project TH 1463/15-1. The computational resources and services used in this work were provided by the VSC (Flemish Supercomputer Centre), funded by the Research Foundation Flanders (FWO) and the Flemish Government, department EWI.

\section{REFERENCES}

(1) Diercks, C.; Yaghi, O. The Atom, the Molecule, and the Covalent Organic Framework. Science 2017, 355 (6328), No. eaal1585.

(2) Krishnaraj, C.; Sekhar Jena, H.; Leus, K.; Van Der Voort, P. Covalent Triazine Frameworks - A Sustainable Perspective. Green Chem. 2020, 22, 1038-1071.

(3) Zhu, S.; Wang, D. Photocatalysis: Basic Principles, Diverse Forms of Implementations and Emerging Scientific Opportunities. Adv. Energy Mater. 2017, 7 (23), 1700841.

(4) Xu, C.; Ravi Anusuyadevi, P.; Aymonier, C.; Luque, R.; Marre, S. Nanostructured Materials for Photocatalysis. Chem. Soc. Rev. 2019, 48 (14), 3868-3902.

(5) Zhi, Y.; Li, Z.; Feng, X.; Xia, H.; Zhang, Y.; Shi, Z.; Mu, Y.; Liu, $X$. Covalent Organic Frameworks as Metal-Free Heterogeneous Photocatalysts For Organic Transformations. J. Mater. Chem. A 2017, 5 (44), 22933-22938.

(6) Li, S.; Li, L.; Li, Y.; Dai, L.; Liu, C.; Liu, Y.; Li, J.; Lv, J.; Li, P.; Wang, B. Fully Conjugated Donor-Acceptor Covalent Organic Frameworks For Photocatalytic Oxidative Amine Coupling And Thioamide Cyclization. ACS Catal. 2020, 10, 8717-8726.
(7) Lei, K.; Wang, D.; Ye, L.; Kou, M.; Deng, Y.; Ma, Z.; Wang, L.; Kong, Y. A Metal-Free Donor-Acceptor Covalent Organic Framework Photocatalyst For Visible-Light-Driven Reduction of CO2 With H2O. ChemSusChem 2020, 13 (7), 1725-1729.

(8) Pachfule, P.; Acharjya, A.; Roeser, J.; Sivasankaran, R.; Ye, M.; Brückner, A.; Schmidt, J.; Thomas, A. Donor-Acceptor Covalent Organic Frameworks For Visible Light Induced Free Radical Polymerization. Chemical Science 2019, 10 (36), 8316-8322.

(9) Pachfule, P.; Acharjya, A.; Roeser, J.; Langenhahn, T.; Schwarze, M.; Schomäcker, R.; Thomas, A.; Schmidt, J. Diacetylene Functionalized Covalent Organic Framework (COF) For Photocatalytic Hydrogen Generation. J. Am. Chem. Soc. 2018, 140 (4), 1423-1427.

(10) Yang, S.; Hu, W.; Zhang, X.; He, P.; Pattengale, B.; Liu, C.; Cendejas, M.; Hermans, I.; Zhang, X.; Zhang, J.; Huang, J. 2D Covalent Organic Frameworks As Intrinsic Photocatalysts For Visible Light-Driven CO2 Reduction. J. Am. Chem. Soc. 2018, 140 (44), 14614-14618.

(11) Zhang, Y.; Hu, Y.; Zhao, J.; Park, E.; Jin, Y.; Liu, Q.; Zhang, W. Covalent Organic Framework-Supported $\mathrm{Fe}-\mathrm{TiO} 2$ Nanoparticles as Ambient-Light-Active Photocatalysts. J. Mater. Chem. A 2019, 7 (27), 16364-16371.

(12) Bi, S.; Thiruvengadam, P.; Wei, S.; Zhang, W.; Zhang, F.; Gao, L.; Xu, J.; Wu, D.; Chen, J.; Zhang, F. Vinylene-Bridged TwoDimensional Covalent Organic Frameworks Via Knoevenagel Condensation Of Tricyanomesitylene. J. Am. Chem. Soc. 2020, 142 (27), 11893-11900.

(13) Vardhan, H.; Verma, G.; Ramani, S.; Nafady, A.; Al-Enizi, A.; Pan, Y.; Yang, Z.; Yang, H.; Ma, S. Covalent Organic Framework Decorated With Vanadium As A New Platform For Prins Reaction And Sulfide Oxidation. ACS Appl. Mater. Interfaces 2019, 11 (3), 3070-3079.

(14) Li, Z.; Zhi, Y.; Shao, P.; Xia, H.; Li, G.; Feng, X.; Chen, X.; Shi, Z.; Liu, X. Covalent Organic Framework As An Efficient, Metal-Free, Heterogeneous Photocatalyst For Organic Transformations Under Visible Light. Appl. Catal., B 2019, 245, 334-342.

(15) Liu, Z.; Su, Q.; Ju, P.; Li, X.; Li, G.; Wu, Q.; Yang, B. A Hydrophilic Covalent Organic Framework for Photocatalytic Oxidation of Benzylamine In Water. Chem. Commun. 2020, 56 (5), $766-769$.

(16) Shanley, E. Hydrogen Peroxide. J. Chem. Educ. 1951, 28 (5), 260.

(17) Ntainjua, E.; Piccinini, M.; Freakley, S.; Pritchard, J.; Edwards, J.; Carley, A.; Hutchings, G. Direct Synthesis Of Hydrogen Peroxide Using Au-Pd-Exchanged And Supported Heteropolyacid Catalysts At Ambient Temperature Using Water As Solvent. Green Chem. 2012, 14 (1), 170-181.

(18) Pizzutilo, E.; Kasian, O.; Choi, C.; Cherevko, S.; Hutchings, G.; Mayrhofer, K.; Freakley, S. Electrocatalytic Synthesis of Hydrogen Peroxide on Au-Pd Nanoparticles: From Fundamentals to Continuous Production. Chem. Phys. Lett. 2017, 683, 436-442.

(19) Hou, H.; Zeng, X.; Zhang, X. Production of Hydrogen Peroxide by Photocatalytic Processes. Angew. Chem., Int. Ed. 2020, 59, 1735617376.

(20) Chen, X.; Kuwahara, Y.; Mori, K.; Louis, C.; Yamashita, H. A Hydrophobic Titanium Doped Zirconium-based Metal Organic Framework for Photocatalytic Hydrogen Peroxide Production in a Two-Phase System. J. Mater. Chem. A 2020, 8, 1904-1910.

(21) Isaka, Y.; Kawase, Y.; Kuwahara, Y.; Mori, K.; Yamashita, H. Two-Phase System Utilizing Hydrophobic Metal-Organic Frameworks (MOFs) for Photocatalytic Synthesis of Hydrogen Peroxide. Angew. Chem., Int. Ed. 2019, 58 (16), 5402-5406.

(22) Shiraishi, Y.; Kanazawa, S.; Sugano, Y.; Tsukamoto, D.; Sakamoto, H.; Ichikawa, S.; Hirai, T. Highly Selective Production of Hydrogen Peroxide On Graphitic Carbon Nitride (g-C3N4) Photocatalyst Activated By Visible Light. ACS Catal. 2014, 4 (3), 774-780.

(23) Michaelis, L.; Schubert, M.; Granick, S. The Free Radicals of The Type of Wurster's Salts. J. Am. Chem. Soc. 1939, 61 (8), 19811992. 
(24) Uebe, M.; Kato, T.; Tanaka, K.; Ito, A. 9,10-Diaminoanthracenes Revisited: The Influence Of n-Substituents on Their Electronic States. Chem. - Eur. J. 2016, 22 (52), 18923-18931.

(25) Munday, R. Generation Of Superoxide Radical, Hydrogen Peroxide And Hydroxyl Radical During The Autoxidation Of $\mathrm{N}, \mathrm{N}, \mathrm{N}^{\prime}, \mathrm{N}^{\prime}$-Tetramethyl-P-Phenylenediamine. Chem.-Biol. Interact. 1988, 65 (2), 133-143.

(26) Noto, N.; Tanaka, Y.; Koike, T.; Akita, M. Strongly Reducing (Diarylamino)Anthracene Catalyst for Metal-Free Visible-Light Photocatalytic Fluoroalkylation. ACS Catal. 2018, 8 (10), 94089419.

(27) Tian, Y.; Xu, S.; Liang, R.; Qian, C.; Jiang, G.; Zhao, X. Construction of Two Heteropore Covalent Organic Frameworks with Kagome Lattices. CrystEngComm 2017, 19 (33), 4877-4881.

(28) Jin, E.; Geng, K.; Lee, K.; Jiang, W.; Li, J.; Jiang, Q.; Irle, S.; Jiang, D. Topology-Templated Synthesis of Crystalline Porous Covalent Organic Frameworks. Angew. Chem. 2020, 132 (29), 12260-12267.

(29) Keller, N.; Sick, T.; Bach, N.; Koszalkowski, A.; Rotter, J.; Medina, D.; Bein, T. Dibenzochrysene Enables Tightly Controlled Docking and Stabilizes Photoexcited States in Dual-Pore Covalent Organic Frameworks. Nanoscale 2019, 11 (48), 23338-23345.

(30) Sasaki, S.; Hattori, K.; Igawa, K.; Konishi, G. Directional Control Of $\Pi$-Conjugation Enabled by Distortion of the Donor Plane in Diarylaminoanthracenes: A Photophysical Study. J. Phys. Chem. A 2015, 119 (20), 4898-4906.

(31) Lambert, C.; Risko, C.; Coropceanu, V.; Schelter, J.; Amthor, S.; Gruhn, N.; Durivage, J.; Brédas, J. Electronic Coupling In Tetraanisylarylenediamine Mixed-Valence Systems: The Interplay Between Bridge Energy And Geometric Factors. J. Am. Chem. Soc. 2005, 127 (23), 8508-8516.

(32) Vanduyfhuys, L.; Vandenbrande, S.; Verstraelen, T.; Schmid, R.; Waroquier, M.; Van Speybroeck, V. QuickFF: A Program for a Quick and Easy Derivation of Force Fields for Metal-Organic Frameworks from ab initio Input. J. Comput. Chem. 2015, 36 (13), $1015-1027$.

(33) Vanduyfhuys, L.; Vandenbrande, S.; Wieme, J.; Waroquier, M.; Verstraelen, T.; Van Speybroeck, V. Extension of the QuickFF Force Field Protocol for an Improved Accuracy of Structural, Vibrational, Mechanical and Thermal Properties of Metal-Organic Frameworks. J. Comput. Chem. 2018, 39 (16), 999-1011.

(34) Wang, X.; Chen, L.; Chong, S.; Little, M.; Wu, Y.; Zhu, W.; Clowes, R.; Yan, Y.; Zwijnenburg, M.; Sprick, R.; Cooper, A. SulfoneContaining Covalent Organic Frameworks For Photocatalytic Hydrogen Evolution From Water. Nat. Chem. 2018, 10 (12), 1180-1189.

(35) Stegbauer, L.; Zech, S.; Savasci, G.; Banerjee, T.; Podjaski, F.; Schwinghammer, K.; Ochsenfeld, C.; Lotsch, B. V. Tailor-Made Photoconductive Pyrene-Based Covalent Organic Frameworks for Visible-Light Driven Hydrogen Generation. Adv. Energy Mater. 2018, 8,1703278 .

(36) Hankin, A.; Bedoya-Lora, F. E.; Alexander, J. C.; Regoutz, A.; Kelsall, G. H. Flat band potential determination: avoiding the pitfalls. J. Mater. Chem. A 2019, 7, 26162-26176.

(37) Kofuji, Y.; Isobe, Y.; Shiraishi, Y.; Sakamoto, H.; Ichikawa, S.; Tanaka, S.; Hirai, T. Hydrogen Peroxide Production On A Carbon Nitride-Boron Nitride-Reduced Graphene Oxide Hybrid Photocatalyst Under Visible Light. ChemCatChem 2018, 10 (9), 20702077.

(38) Zeng, X.; Liu, Y.; Kang, Y.; Li, Q.; Xia, Y.; Zhu, Y.; Hou, H.; Uddin, M. H.; Gengenbach, T. R.; Xia, D.; Sun, C.; Mccarthy, D. T.; Deletic, A.; Yu, J.; Zhang, X. Simultaneously Tuning Charge Separation and Oxygen Reduction Pathway on Graphitic Carbon Nitride by Polyethylenimine for Boosted Photocatalytic Hydrogen Peroxide Production. ACS Catal. 2020, 10 (6), 3697-3706.

(39) Kaynan, N.; Berke, B.; Hazut, O.; Yerushalmi, R. Sustainable Photocatalytic Production of Hydrogen Peroxide from Water And Molecular Oxygen. J. Mater. Chem. A 2014, 2 (34), 13822-13826.
(40) Kim, H.-I.; Choi, Y.; Hu, S.; Choi, W.; Kim, J.-H. Photocatalytic Hydrogen Peroxide Production by Anthraquinone-Augmented Polymeric Carbon Nitride. Appl. Catal., B 2018, 229, 121-129.

(41) Yang, Y.; Zhang, C.; Huang, D.; Zeng, G.; Huang, J.; Lai, C.; Zhou, C.; Wang, W.; Guo, H.; Xue, W.; Deng, R.; Cheng, M.; Xiong, W. Boron Nitride Quantum Dots Decorated Ultrathin Porous g$\mathrm{C}_{3} \mathrm{~N}_{4}$ : Intensified Exciton Dissociation and Charge Transfer for Promoting Visible-Light-Driven Molecular Oxygen Activation. Appl. Catal., B 2019, 245, 87-99.

(42) Fu, Y.; Liu, C.; Zhang, M.; Zhu, C.; Li, H.; Wang, H.; Song, Y.; Huang, H.; Liu, Y.; Kang, Z. Photocatalytic H2O2 And H2 Generation From Living Chlorella Vulgaris And Carbon Micro Particle Comodified G-C3N4. Adv. Energy Mater. 2018, 8 (34), 1802525.

(43) Shiraishi, Y.; Takii, T.; Hagi, T.; Mori, S.; Kofuji, Y.; Kitagawa, Y.; Tanaka, S.; Ichikawa, S.; Hirai, T. Resorcinol-Formaldehyde Resins As Metal-Free Semiconductor Photocatalysts For Solar-ToHydrogen Peroxide Energy Conversion. Nat. Mater. 2019, 18 (9), 985-993.

(44) Goto, H.; Hanada, Y.; Ohno, T.; Matsumura, M. Quantitative Analysis of Superoxide Ion and Hydrogen Peroxide Produced from Molecular Oxygen on Photoirradiated TiO2 Particles. J. Catal. 2004, 225 (1), 223-229. 